\title{
HE6/GPR64 adhesion receptor co-localizes with apical and subapical F-actin scaffold in male excurrent duct epithelia
}

\author{
Christiane Kirchhoff, Caroline Osterhoff and Annemarie Samalecos \\ IHF Institute for Hormone and Fertility Research, University of Hamburg, D-22529 Hamburg, Germany \\ Correspondence should be addressed to C Kirchhoff at Universitätsklinikum Hamburg-Eppendorf, \\ Martinistraße 52,D-20246 Hamburg, Germany; Email: c.kirchhoff@uke.uni-hamburg.de
}

C Kirchhoff is now at Department of Andrology, University Hospital Hamburg-Eppendorf, Hamburg, Germany

\begin{abstract}
A role for HE6/GPR64 in male excurrent ducts in the regulation of water balance was suggested from targeted gene mutation in the mouse. Results of the present immunolocalization study strengthen this hypothesis. Employing monospecific antibodies and laser confocal microscopy, we studied the localization of the receptor protein in the human and wild-type mouse ductuli efferentes and epididymis. We show that HE6/GPR64 is specifically associated with cell types and subcellular domains involved in the process of fluid reabsorption. In the mouse, dual labelling with anti-tubulin antibodies revealed that HE6/GPR64 was absent from the (kino-) cilia of ciliated cells. Instead, the receptor protein accumulated in the non-ciliated principal cells. Specifically, strong immunofluorescence was observed in the apical compartment of these cells. Dual labelling with phalloidin and anti-ezrin antibodies revealed that in the mouse the bulk amount of HE6/GPR64 protein co-localized with the F-actin-ezrin scaffold in brush border-like microvilli of ductuli efferentes and long stereocilia of the epididymis proper. In the ductuli efferentes, HE6/GPR64 also co-localized with the subapical F-actin network immediately below the microvilli. Comparable immunostaining patterns were observed in human and mouse; however, a specific feature of the human ductuli efferentes was an intense HE6/GPR64-related labelling of crypt-like grooves or furrows of hitherto unknown function.
\end{abstract}

Reproduction (2008) 136 235-245

\section{Introduction}

The production of spermatozoa in the testis is accompanied by abundant fluid secretion (Setchell et al. 1969), of which between 50 and $90 \%$, depending upon species and study technique, are reabsorbed within the proximal part of the male gential tract. The importance of fluid reabsorption for male reproduction is emphasized by animal models that exhibit male infertility or subfertility because of a perturbed water balance (Lubahn et al. 1993, Hess et al. 1997, Davies et al. 2004). Fluid reabsorption occurring in the ductuli efferentes and epididymis is a complex and tightly regulated phenomenon. Chronic fluid control is largely dependent on sex hormones, while local acute regulation seems to be determined by load and rate of flow (Clulow et al. 1996; for a review, see Hess 2003). On a cellular level, three major mechanisms seem to be involved: (i) transcellular transport via apical and basolateral aquaporins (for a review, see Da Silva et al. 2006), (ii) cytoskeletondependent fluid phase endocytosis (Hermo et al. 1994), and (iii) paracellular transport through apical junctional complexes (Ilio \& Hess 1992). Transport regulation in the ductuli efferentes seems to be mediated by cAMP (Man et al. 2003) and probably other signal transduction systems. However, a local flow sensor is unknown.

HE6/GPR64, orphan member of the LNB-TM7(B2) subfamily of G-protein-coupled receptors (GPCRs; for a review, see Gottwald et al. 2006, Kirchhoff et al. 2006) was suggested to function in the control of water balance and fluid reabsorption in the male excurrent ducts (Davies et al. 2004). In the human and rodents, HE6/GPR64 mRNA is highly expressed in the epithelia of ductuli efferentes and proximal epididymis, but is not normally found in other tissues of the adult (Osterhoff et al. 1997, Obermann et al. 2003). A role for the receptor in fluid reabsorption was suggested from the phenotype of HE6/Gpr64 knockout (KO) mice, which revealed male infertility correlated with spermatozoa stasis and fluid back-up in the rete testis (Davies et al. 2004). Further support came from an altered gene expression pattern in the epididymides of HE6/Gpr64 KO mice (Davies et al. 2007). Significant downregulation of genes was observed in the $\mathrm{KO}$ organs whose expression depended upon testicular luminal factors (Davies et al. 2007). The list of downregulated gene products included claudin-10, member of a family of 
tight junction proteins. Claudin proteins create the tissue-specific and regional differences in paracellular conductance of various epithelia, including epithelia of the male genital tract (Inai et al. 2005, Holmes et al. 2006).

To better understand the functional role of HE6/GPR64, an immunolocalization study was performed here to reveal the cell types and subcellular compartments along the male genital tract that contained the receptor protein. The epithelia of the ductuli efferentes are mainly composed of two cell types, ciliated and non-ciliated (for a review, see Ilio \& Hess 1994). The non-ciliated cells play a specific role in fluid take-up. So far, most channels and transport proteins have been detected in these cells (for a review, see Da Silva et al. 2006). The ciliated cells seem to have a role in moving fluid and spermatozoa through the ducts but may, to a lesser extent, also take up material (for a review, see Ilio \& Hess 1994). The epithelium of the epididymis is mainly composed of principal and basal cells (Robaire \& Hermo 1988). Other cell types such as the narrow, clear and halo cells are scattered along the duct in lesser number, their structural and molecular features likewise, suggesting that they perform specialized functions. We show here by laser confocal microscopy the co-localization of HE6/GPR64-related protein with the apical and subapical F-actin cytoskeleton of non-ciliated principal cells in the ductuli efferentes and epididymis.

\section{Results \\ Localization of HE6/GPR64-related protein in human ductuli efferentes and epididymis}

Immunoperoxidase staining was performed on paraffin tissue sections through the proximal human epididymis. Polyclonal anti-N2 and A antibodies from rabbits were employed (Obermann et al. 2003), which had been raised against discrete peptide epitopes of the ecto- and endosubunit of the heterodimeric HE6/GPR64 receptor protein respectively. A complex regionalized staining pattern was observed, which was congruent with both HE6/GPR64-directed antibodies (Fig. 1). The immunostaining patterns observed in two different human subjects were also very similar. Control stainings using pre-immune sera as well as antibody preparations, which had been pre-absorbed with the corresponding $\mathrm{N} 2$ and A oligopeptides (Fig. 1; compare Obermann et al. 2003) suggested that the regionalized staining pattern described below was specific.

HE6/GPR64-related immunoperoxidase staining was restricted to the duct epithelia; intertubular tissue and duct lumina showed no reaction above background (Fig. 1). Different types of tubules were distinguished on the basis of their epithelial morphology and luminal contents. In the proximal most part of the human caput region, a solitary cystic projection possibly represented a blind-ending
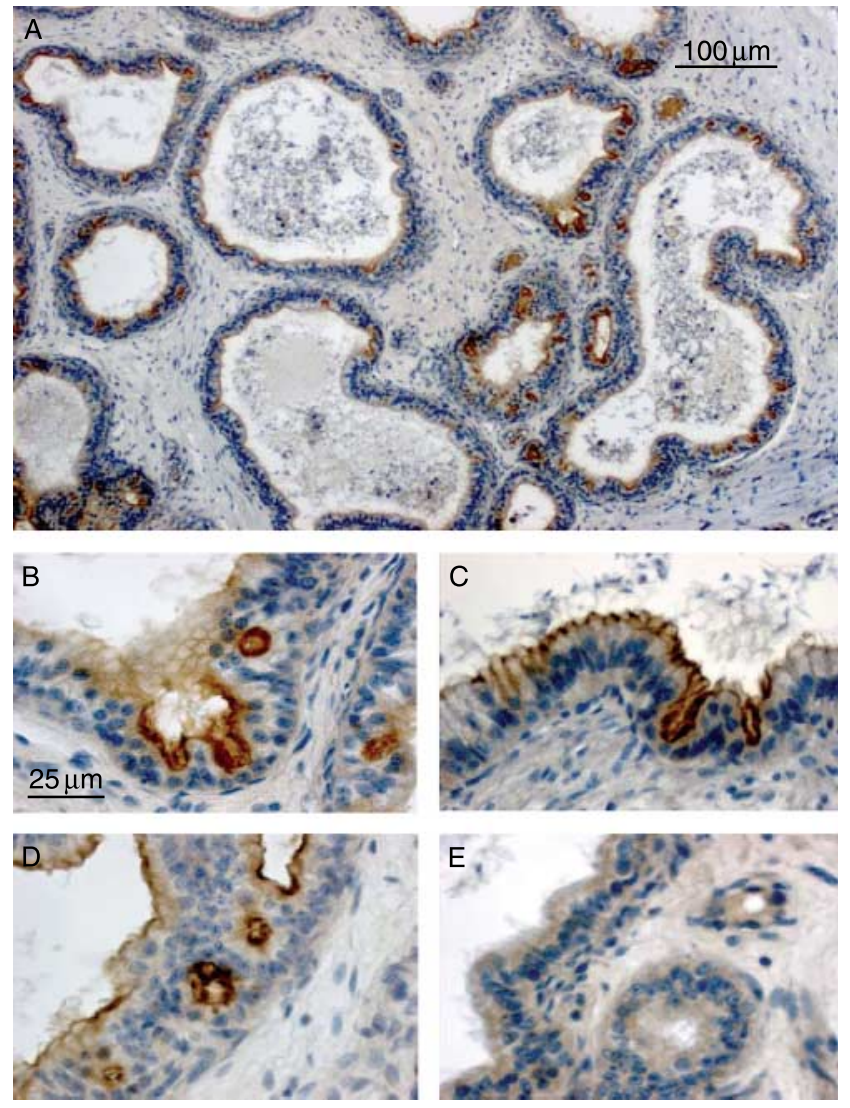

Figure $1 \mathrm{Immunoperoxidase} \mathrm{stainings} \mathrm{of} \mathrm{human} \mathrm{ductuli} \mathrm{efferentes} \mathrm{for}$ HE6/GPR64-related protein employing N2 and A antibody preparations. (A) Positive reaction of type I and III-like epithelia using the N2 antibody. Specific staining was restricted to the apical part of duct epithelia; unspecific staining of blood vessels is occasionally observed. (B) Detail of the above illustration showing strong apical staining in crypt-like grooves or furrows of type I-like epithelia.

(C) Comparable staining results were obtained with the A antibody on adjacent cross-section. (D) Immunopositive reaction of A antibody in sections through narrow ducts resembling the so-called 'microcanals'. (E) Negative control staining on adjacent cross-section. Scale bars: (A) $100 \mu \mathrm{m}$; (B-E) $25 \mu \mathrm{m}$.

efferent ductule. Both the uniform cuboidal epithelium that appeared immature and the luminal contents of this structure that lacked spermatozoa were negative for HE6/GPR64 (Fig. 2). This was possibly due to the lack of luminal fluids from the testis. In comparison, the majority of cross-sections through the ductuli efferentes were strongly immunopositive for HE6/GPR64. Maximum reactivity was seen in the apical most (adluminal) parts of type I epithelia (compare Yeung et al. 1991) that are characterized by a highly irregular outline (Figs 1 and 2). The irregular outline obviously resulted from variable heights of the epithelial cells (Holstein 1969), the epithelium generally appearing as thrown into numerous folds, which formed crests and grooves. In this area, HE6/GPR64-related immunoreactivity specifically accumulated in deep, crypt-like grooves or furrows; crest-like structures showed a weaker staining. 

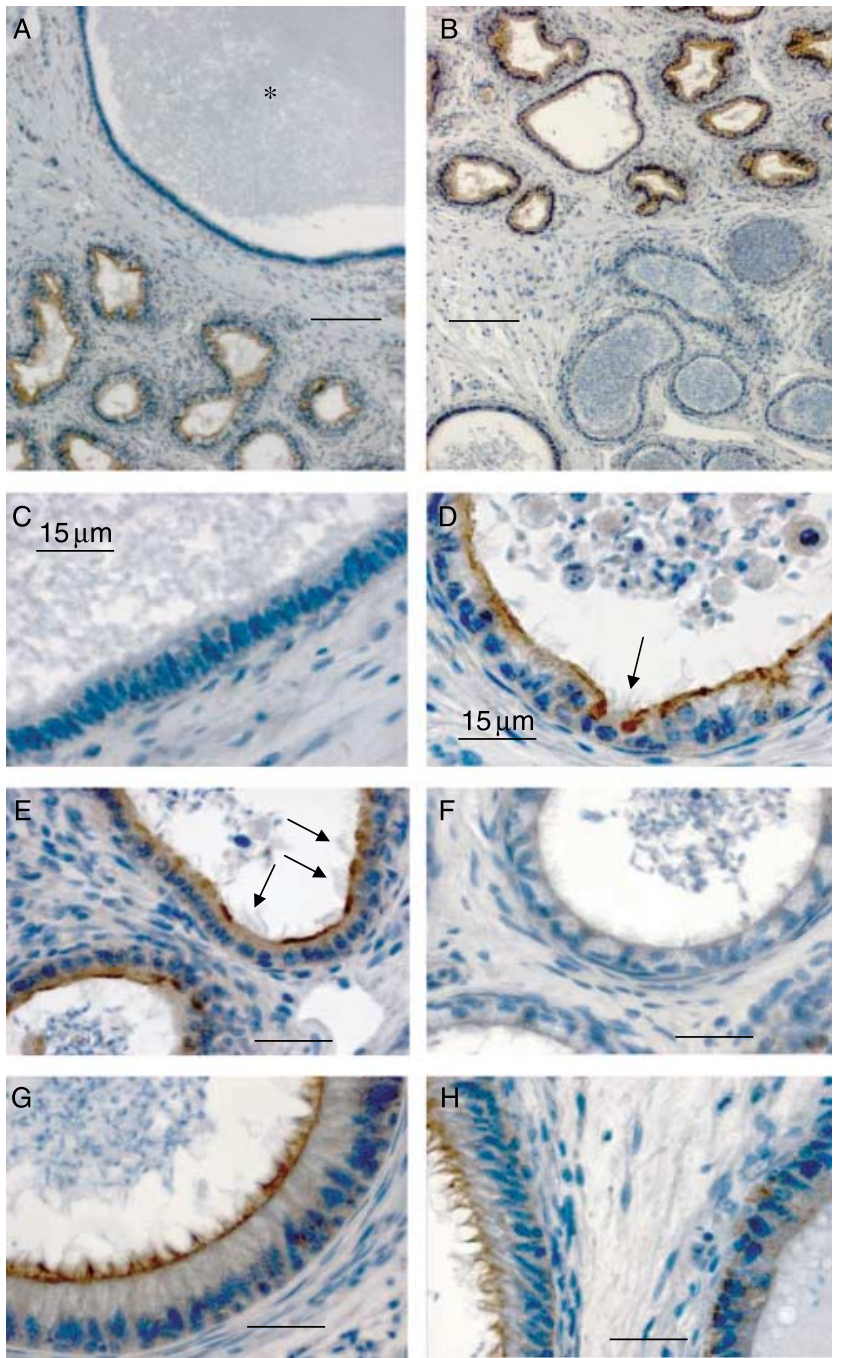

Figure 2 Region-specific pattern of HE6/GPR64-related immunoperoxidase staining in subsequent regions of human male excurrent ducts. (A) Cross-section through proximal most part of human caput comprising ductuli efferentes and a blind-ending tubule with widely dilated lumen $\left({ }^{*}\right)$. (B) Cross-section showing strongly immunopositive type I epithelia that are directly adjacent to HE6/GPR64-negative epithelia of blind-ending tubules; note densely packed spermatozoa in lumen. (C) Detail of blind-ending tubule; note negative cuboidal epithelium and the absence of cellular material in lumen. (D and E) Details showing type III-like epithelia with ciliated cells. Arrows point to apparently negative cilia. (F) Detail showing negative epithelium of adjacent tubule. (G) Cross-section through proximal epididymal duct region; note strongly immunopositive 'stereocilia' of duct epithelium. (H) Cross-sections through epididymal duct in corpus region; note diminished apical staining in region with shorter microvilli. Scale bars: (A and B) $100 \mu \mathrm{m}$; (C and D) $15 \mu \mathrm{m}$;

(E-H) $25 \mu \mathrm{m}$.

A specifically strong reaction was also observed in the occasionally occurring narrow ductuli that are seen at the periphery of the wider efferent ducts, possibly representing planar sections through the deep grooves (Fig. 1). Similar structures occurring in the ductuli efferentes of animal models had previously been referred to as 'microcanals'. These canals may form as a consequence of ductular obstruction at exposure to toxicants (for a review, see Hess \& Nakai 2000). However, in the two human tissues studied here, no obstructions and/or fibrotic lesions were obvious, which were indicative of such lesions.

Apical HE6/GPR64 immunoreactivity was also prevailing in the duct epithelia which showed a more regular outline of their epithelium (Fig. 2). Ciliated cells were frequent in this type of epithelium (Fig. 2); however, from bright-field microscopy, it was not possible to unequivocally discern HE6/GPR64-positive and HE6/GPR64negative apical differentiations. On the other hand, adjacent ductular cross-sections were clearly HE6/GPR64 negative, which showed a flat cuboidal epithelium and contained dense masses of luminal spermatozoa (Fig. 2). These unstained epithelia apparently also delineated blind-ending ductuli as described by Yeung et al. (1991), while the HE6/GPR64-positive areas resembled cross-sections of type I and III epithelia.

Further downstream, the most pronounced HE6/GPR64 immunoreactivity resided in the apical 'stereocilia' that actually represented long branched microvilli of the epididymis proper (Fig. 2). As these structures occupied much of the neighbouring apical surfaces, it was not possible to decide from bright-field microscopy whether interspersed narrow-type apical mitochondrial-rich cells were positive or negative for HE6/GPR64. The gradually decreasing length of the 'stereocilia' was accompanied by a decreasing gradient of HE6/GPR64-related immunoreactivity along the longitudinal axis of the duct epithelium; no other regional differences were obvious. Further distal in the human corpus epididymidis, HE6/GPR64-specific staining gradually disappeared.

\section{Cell type-specific expression of HE6/GPR64 along the male excurrent ducts of the mouse}

To better resolve the cell type specificity and subcellular location of the HE6/GPR64 receptor, we studied mouse organs that had been fixed by cardiac vascular perfusion; the quality of immersion-fixed human tissues was not sufficient in this regard (data not shown). Immunofluorescence labelling was performed employing the anti-mA23 antibody, which was raised against the third extracellular loop of the murine HE6/GPR64 counterpart (Obermann et al. 2003). Antibodies raised against the $\mathrm{N}$-terminus of the murine HE6/GPR64 counterpart (compare Obermann et al. 2003, Davies et al. 2004) yielded similar results, albeit with a higher background (data not shown). As was already observed in the human, specifically strong HE6/GPR64-related immunoreactivity was restricted to the epithelia of ductuli efferentes and proximal epididymides (Fig. 3A, overview). Organs from three animals were analysed in parallel, and the results were consistent. 

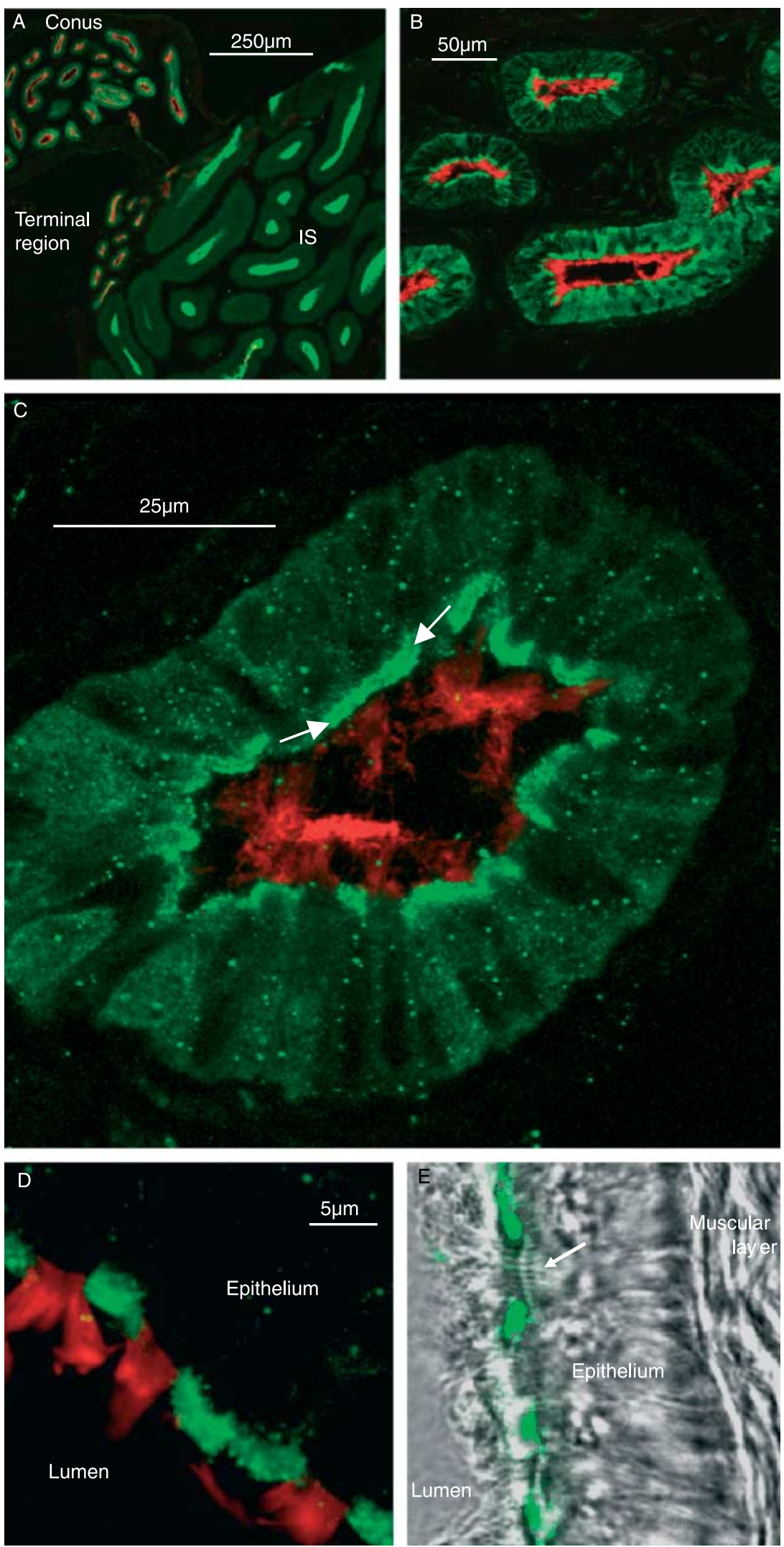

Figure 3 Dual labelling of HE6/GPR64 receptor protein and acetylated tubulin in male excurrent ducts of the mouse. Cy2conjugated second antibody was used in combination with $\mathrm{mA} 23$ antibody (green fluorescence) and Cy3-conjugated second antibody in combination with acetylated tubulin (red fluorescence). (A) Overview showing conus region and terminal region of ductuli efferentes plus initial segment (IS) of epididymis. HE6/GPR64-related fluorescence (green) is present in epithelia of ductuli efferentes plus IS epithelium, while acetylated tubulin-related fluorescence (red) is restricted to ductuli efferentes. (B) Ductular crosssections of conus region; cells with prominent apical HE6/GPR64 staining are in close vicinity to others in which entire cell bodies are labelled. HE6/GPR64 and tubulin fluorescence do not co-localize on merged confocal image. (C) HE6/GPR64-related immunofluorescence is characterized by a dual apical structure intersected by a dark line (highlighted by arrows). This line probably marks the frontier between brush border-like microvilli and the subapical (endosomal?) compartment. The dual structure is most intensely stained in cross-sections of the conus region of ductuli efferentes. (D) Detail showing that HE6/GPR64-related (green) and acetylated tubulin-related fluorescence are associated with alternating apical structures. (E) Overlay of HE6/GPR64-related immunofluorescence and differential interference contrast image suggests that the receptor is localized in the apical domain of the non-ciliated cell type and not in ciliated cells (arrow). 
We performed confocal microscopy with dual fluorescence labelling, combining the mA23 antibody with a monoclonal $\boldsymbol{\alpha}$-tubulin antibody, which had been raised against acetylated $\boldsymbol{\alpha}$-tubulin. This modified tubulin isoform accumulates only in the stabile microtubules of flagella and cilia but not in the dynamic microtubules (Piperno \& Fuller 1985; see Materials and Methods). In our study, acetylated $\boldsymbol{\alpha}$-tubulin was a highly specific marker of the ciliated cells (Fig. 3) that are interspersed in the epithelium of the ductuli efferentes at varying proportions, depending upon region (compare Ilio \& Hess 1994). The bright red apical structures represented the tufts of (kino-) cilia, each of which contained an axoneme of stabile microtubules (Fig. 3B-E).

Confocal imaging revealed that the HE6/GPR64related green fluorescence did not co-localize with these tufts (Fig. 3B-D). Rather, the receptor protein accumulated in alternating apical structures located in neighbouring non-ciliated cells of the ductuli efferentes epithelium (Fig. 3D). In the non-ciliated cells of the conus region, a dual apical structure was most prominently stained for HE6/GPR64, which was intersected by a frontier between the brush border-like microvilli and the subapical (endosomal?) compartment (Fig. 3C). This frontier was visible as a dark line between these two subcellular domains. Although HE6/GPR64related fluorescence was prevailing in the apical cellular domain, it was occasionally observed also in the cellular bodies and in the basolateral areas of some ductular cross-sections (Fig. 3B). In comparison, the acetylated tubulin was restricted to (kino-) cilia.

In the initial segment (IS) of the epididymis proper, HE6/GPR64-related fluorescence was largely restricted to the long stereocilia (Fig. 4). Cellular bodies and basolateral membrane domains of the principal cells were barely fluorescent; occasionally observed HE6/GPR64-positive spots resembled transporting vesicles. Basal cells were HE6/GPR64-negative. Interspersed in the IS epithelium were a few tall and slender cells that were strongly positive for acetylated $\alpha$-tubulin (Fig. 4). These cells resembled apical or narrow cells. As their apical tubulin fluorescence was partially superimposed by long and brightly stained apical projections of adjacent HE6/GPR64-positive principal cells, the presence or absence of the HE6/GPR64 receptor protein in these cells could not be unequivocally decided.

\section{Association of HE6/GPR64 with the apical F-actin-ezrin scaffold}

To reveal the nature of the apical HE6/GPR64-positive structures, dual labelling of mouse ductuli efferentes and epididymal duct epithelia was performed with either phalloidin (for a review, see Wieland 1987) or with antiezrin antibodies (Berryman et al. 1993). It is well documented that non-ciliated cells in both the ductuli efferentes and the epididymal duct proper carry microvilli of different lengths (for a review, see Robaire \& Hermo 1988), which are characterized by parallel F-actin bundles. Ezrin, a minor component of microvilli in the male excurrent ducts (Höfer \& Drenckhahn 1996), is considered to be an organizer of the brush border and/or actin terminal web. More recently, ezrin was also found in the apical domain of specialized ciliated cells (Huang et al. 2003).

The anti-ezrin antibody stained the epithelia of both ductuli efferentes and epididymal duct epithelia (Fig. 5A, overview). In the ductuli efferentes, ezrin was specifically localized to the apical membrane domain (Fig. 5B and C). A prominent basal ezrin staining was additionally observed in the IS of the epididymis that was most probably localized in the basal cells (Fig. 5A). Combining mA23 and ezrin antibodies, HE6/GPR64 co-localized with ezrin in the apical epithelial domains, but not in the basal areas. In the ductuli efferentes, this co-localization was interrupted by interspersed cells that were positive for ezrin but negative for HE6/GPR64 (Fig. 5B and C). These cells most probably represented the ciliated cell type of the ductuli efferentes. Apical ezrin expression had previously been observed in ciliated airway epithelial cells (Huang et al. 2003). In the male genital tract, however, different from the airway epithelium, ezrin appeared to be present also in the nonciliated cells (compare also Höfer \& Drenckhahn 1996).

Combining the mA23 antibody with phalloidin, the HE6/GPR64 receptor co-localized with apical F-actin in both efferent ducts and IS epithelia (Figs 6 and 7). No co-localization was observed in the basal parts of the
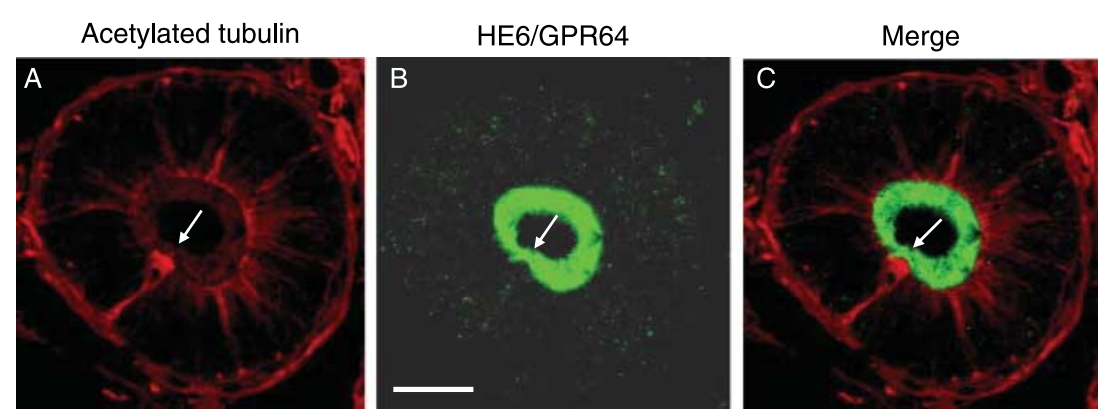

Figure 4 Dual labelling and confocal microscopy of HE6/GPR64 receptor protein (green) and acetylated tubulin (red) in initial segment of mouse epididymis (projections transparent (A and B), overlay fast $(\mathrm{C})$ ). Ductular cross-section reveals that HE6/GPR64-related fluorescence (green) is largely restricted to apical microvilli (='stereocilia') of principal cells. Arrow points to tip of interspersed narrow-type apical cell. Scale bar: $20 \mu \mathrm{m}$. 

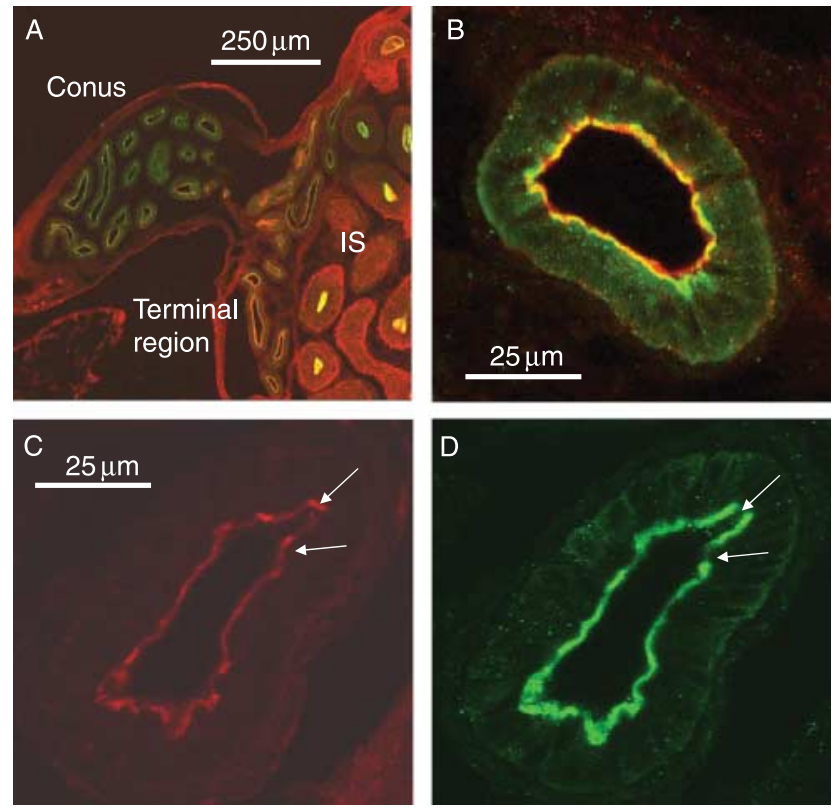

Ezrin

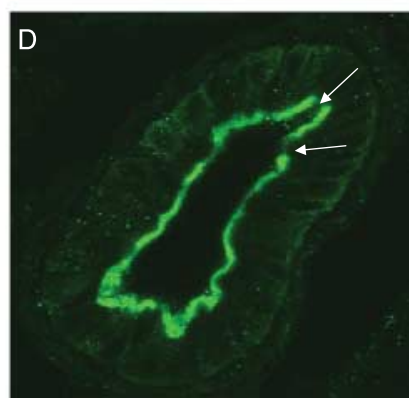

HE6/GPR64

Figure 5 Dual labelling of HE6/GPR64 receptor protein and ezrin in male excurrent ducts of the mouse. Cy2-conjugated second antibody was used in combination with mA23 antibody (green fluorescence) and Cy3-conjugated second antibody in combination with ezrin MAB (red fluorescence); co-localization is indicated by yellow fluorescence. (A) Overview shows conus region and terminal region of ductuli efferentes plus initial segment (IS) of epididymis. Epithelial ezrin labelling (red) is highest in IS. Co-localization of ezrin with HE6/GPR64 (yellow) is most prominent in apical microvilli (='stereocilia') of the IS; note also the strong basal ezrin staining in this region (red). (B) In the ductuli efferentes, merged image shows that apical co-localization of HE6/GPR64 receptor protein and ezrin is only partial. (C and D) Arrows highlight cells of mouse efferent duct epithelium in which apical ezrin staining (red) is most prominent, but which seem to be negative for HE6/GPR64 (green). Cross-section shows that these cells are associated with groove or furrow-like structure in duct epithelium.

epithelial cellular bodies or in the muscular layer below the epithelium (Fig. 7). Spherical protrusions occasionally extended into the duct lumen that seemed to be derived from the apexes of scattered epithelial cells (Fig. 7A). These homogenous bleb-like structures were HE6/GPR64 positive but F-actin negative. As the mouse tissues employed in this study had been fixed by cardiac vascular perfusion (see Materials and Methods), it is assumed that the blebs did not represent fixation artefacts. Examining the co-localization of F-actin and HE6/GPR64 more closely, it was most prominent in microvillar shafts and also in a subapical zone immediately below the microvillar brush border in the ductuli efferentes (Fig. 7A). Further downstream in the epididymis proper, HE6/GPR64 protein co-localized with F-actin in the long microvilli (=stereocilia) but not in the subapical zone below the microvilli (Fig. 7B).

In the IS, F-actin-containing dotted structures were disclosed, which were intimately associated with the apical lateral membranes of the epithelium (Fig. 7B).

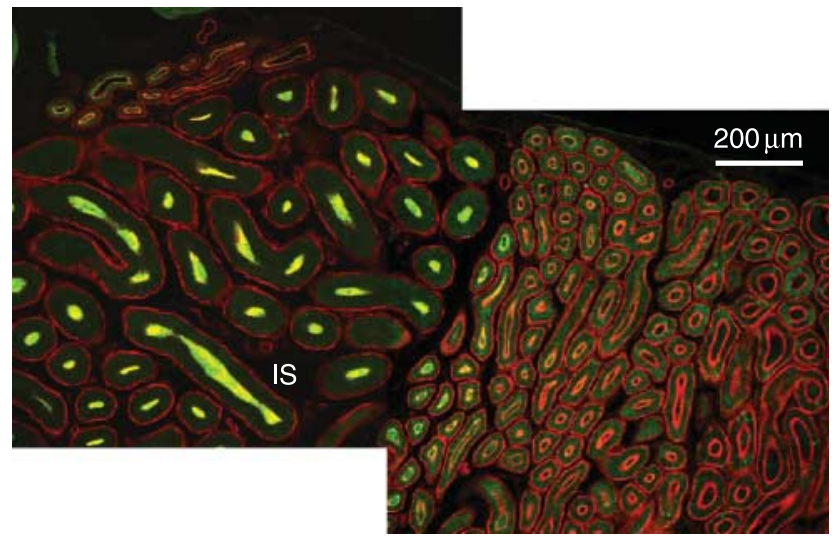

Figure 6 Proximal part of mouse epididymis, including initial segment (IS), after dual labelling for HE6/GPR64 receptor protein and F-actin. Cy2-conjugated second antibody was used in combination with $\mathrm{mA} 23$ antibody (green fluorescence); F-actin was labelled by phalloidin staining (red fluorescence). Note that HE6/GPR64-related fluorescence and co-localization with F-actin (yellow) are most obvious in the long apical microvilli (='stereocilia') of the IS (on the left). In the more distal parts of the caput, HE6/GPR64-related fluorescence is greatly diminished and no longer associated with apical microvilli (on the right).

These prominent dotted structures resembled apical junctional complexes, which appeared to be well developed in this region of the male genital tract; no co-localization with the HE6/GPR64 receptor was observed in these structures. Still further distally, ceasing HE6/GPR64-related immunofluorescence largely resided inside the epithelial cells while apical microvilli appeared less prominently stained. Finally, in the distal caput and corpus regions, only residual HE6/GPR64-related immunofluorescence was observed, which appeared to be no longer associated with the F-actin cytoskeleton.

\section{Discussion}

The present study revealed that HE6/GPR64 accumulates in the apical epithelial domain of the proximal male excurrent duct system. The receptor protein is specifically associated with cell types and subcellular structures that have been implicated in the process of fluid reabsorption. A role for HE6/GPR64 in fluid reabsorption was previously suggested from the infertility phenotype of male KO mice (Davies et al. 2004, 2007). We show here that HE6/GPR64-related protein is highly enriched in the non-ciliated cell type of the ductuli efferentes that is largely involved in fluid reabsorption (for a review, see Da Silva et al. 2006). Apical microvilli plus underlying subapical compartment were most prominently stained in these cells. In comparison, the ciliated cells of the ductuli efferentes were negative for HE6/GPR64. Indeed, these cells have been reported to serve different functions (for a review, see Pastor-Soler et al. 2005). 

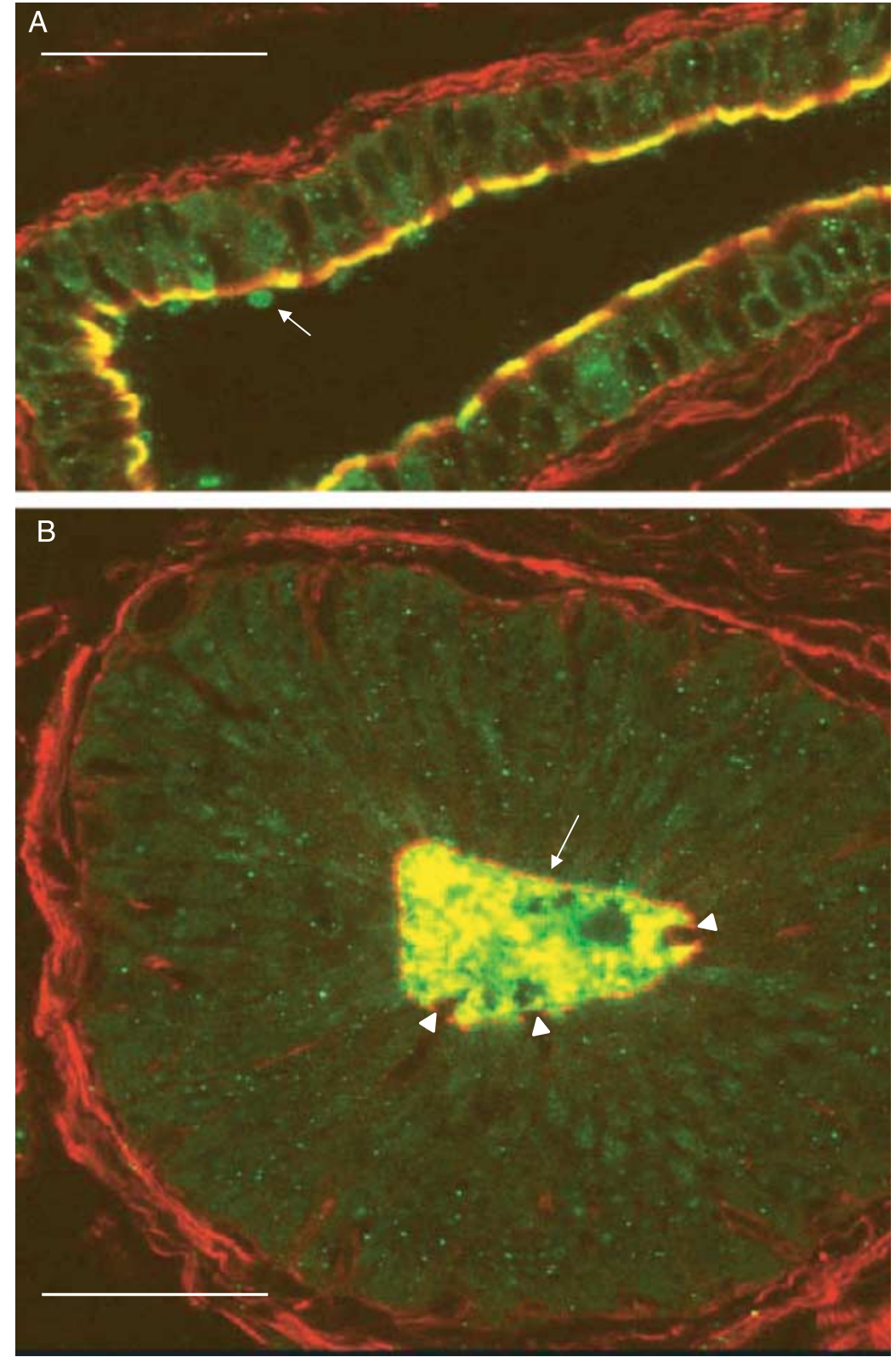

Figure 7 Details of mouse ductuli efferentes and initial segment (IS) after dual labelling for HE6/GPR64 receptor protein (green) and F-actin (red). (A) In cross-section through ductuli efferentes, co-localization of the receptor protein with $\mathrm{F}$-actin is most prominent in microvillar shafts and also in a subapical zone immediately below the microvillar brush border (yellow fluorescence). Cells with apical co-localization alternate with cells where only phalloidin fluorescence (red) is visible. Arrow accentuates HE6/GPR64-positive (green), but F-actin-negative bleb-like structures. (B) In the IS, HE6/GPR64 protein co-localizes with F-actin in the long microvilli (='stereocilia') but not with the subapical zone below the microvilli. Note the F-actin-positive, but HE6/GPR64-negative dotted structures (red), which correspond to the apical junctional complexes (arrow) of the IS epithelium. Arrow heads highlight interspersed narrow-type apical cells. Scale bar: $25 \mu \mathrm{m}$.
In the non-ciliated cells of the ductuli efferentes, a prominent dual apical structure was observed, which was strongly positive for HE6/GPR64. This dual structure probably comprised the apical microvillar brush border plus underlying subapical cytoskeleton. It was hypothesized that microvilli function as sensors to detect and amplify hydrodynamic forces and transmit them to the subapical actin cytoskeleton (Du et al. 2004). The present results on the subcellular distribution of the HE6/GPR64 receptor and its co-localization with F-actin are compatible with such sensor function. Also, a well-developed endocytic apparatus has been described in the ductuli efferentes consisting of subapical tubules and endocytic vacuoles. Our results may thus indicate an intense cell surface receptor internalization that takes place for HE6/ GPR64 in the ductuli efferentes. Spherical protrusions of HE6/GPR64-positive material were occasionally observed in this region that extended into the lumen of the ductuli efferentes. These bleb-like structures may not be an artefact but rather indicate apocrine release of cellular material (Aumüller et al. 1999, Hermo \& Jacks 2002). Alternatively, energy depletion has been suggested to facilitate the formation and detachment of blebs by weakening apical membrane interactions with membrane cytoskeleton linkers, including ezrin (Chen \& Wagner 2001). Further downstream in the epididymal duct proper, principal cells actively secrete and (re)absorb numerous proteins and small molecules (for a review, see Robaire \& 
Hermo 1988). In this region, the dual apical structure was no longer obvious. Rather, HE6/GPR64 was mainly associated with the long highly specialized microvilli of principal cells but not with the subapical cytoplasm.

The present study revealed a comparable regional distribution of HE6/GPR64 in the human and mouse excurrent ducts, underlining the conserved expression characteristics of the orphan receptor (compare also Obermann et al. 2003, Kirchhoff et al. 2006). However, a special feature of HE6/GPR64 expression in the human was also observed. Type I epithelia of the ductuli efferentes, which are characterized by a highly irregular outline (compare Yeung et al. 1991) showed an intense immunostaining of crypt-like grooves or furrows. These apparently human-specific structures that had no obvious counterpart in the mouse were remotely reminiscent of crypts in the intestine. Similar structures were shown in a recent publication on the localization of ion transport-associated proteins in the human ductuli efferentes (Kujala et al. 2007). Although not explicitly mentioned by the authors, the putative anion transporter-1 (SLC26A6) and the $\mathrm{Na}^{+} / \mathrm{H}^{+}$exchanger NHE3 (SLC9A3) seemed to be specifically enriched in cryptlike grooves. Comparable differentiations in the ductuli efferentes of other species are seldom mentioned in the literature (but compare Ilio \& Hess 1994), and their functional significance remains unknown.

The HE6/GPR64 receptor protein seemed to cover the brush border-like microvilli of ductuli efferentes and also the very long and branched 'stereocilia' of the proximal epididymis (Obermann et al. 2003). These apical structures, in addition to their central F-actin bundles, are also enriched in a panel of scaffolding proteins, including ezrin. Using the mouse as a model, our present results confirmed previous localization studies and revealed an intimate association of the HE6/GPR64 receptor with the apical actin-ezrin scaffold. In comparison with F-actin, though, co-localization of HE6/GPR64 with ezrin appeared less continual. An apical area immediately below the ciliated tufts was positive for F-actin and ezrin, but was completely devoid of HE6/GPR64. Indeed, ezrin has been found in the apical domain of specialized ciliated cells of the airway epithelium (Huang et al. 2003) and may thus also be expressed in the ciliated cell type of the ductuli efferentes. A profilin-like protein that was previously suggested to link HE6/GPR64 to the actin cytoskeleton (Kirchhoff et al. 2006), however, could not be verified by co-localization studies (data not shown).

Actin microfilaments are responsible for surface expression, functional activity and intracellular trafficking of numerous ion channels (for a review, see Mazzochi etal. 2006). They may also be involved in the targeting and/or internalization of surface receptors, including HE6/ GPR64. It has long been known that growth factor receptors, like the epidermal growth factor receptor, directly bind to actin in vivo. More recently, a link between GPCRs of the brain and the cortical actin cytoskeleton was also described (Schwabe et al. 2005). To date, however, no information is available concerning the in vivo binding partner(s) of HE6/GPR64, which may be responsible for its specific subcellular localization. Also, no information is as yet available regarding possible determinants on the of HE6/GPR64 molecule itself, which might be involved in the polarized targeting to the apical membrane domain.

Coupling of surface receptors to the apical cellular compartment occurs preferentially in the absence of a ligand; after binding of their specific ligand(s), receptors may become internalized. In this context, it is of interest that cross-sections were commonly encountered within the ductuli efferentes, which showed an intense HE6/GPR64 labelling of entire epithelial cell bodies, including the basolateral domain. These ductuli were often found in close vicinity to others, which showed almost exclusive apical staining. In the epididymis, in comparison, HE6/GPR64-related staining was restricted to the long microvilli of the principal cells while basolateral domains and cellular bodies remained largely unstained. It is thus tempting to speculate that subapical and basolateral stainings within the ductuli efferentes might reflect an internalization of the HE6/GPR64 receptor, which occurred upon interaction with its ligand. This ligand may be no longer available more distally in the luminal fluids of the epididymal duct proper.

It should be considered, however, that HE6/GPR64 is an 'orphan' member of the adhesion GPCRs, and a ligand is presently unknown. Like other members of this subfamily of cell surface receptors, it has a remarkably long $\mathrm{N}$-terminus that may be involved in molecular adhesion. Thus, HE6/GPR64 may also serve a structural function, comparable with the closely related VLGR1 receptor in the ankle links of hair cell stereocilia (for a review, see Vollrath et al. 2007). Indeed, microvilli of various epithelia serve very different functions. They are involved in fluid reabsorption in kidney and intestinal brush borders, in secretion in gastric parietal cells, in chemosensation in taste buds and vomeronasal organ, and in mechanosensation in inner ear hair cells and Merkel cells. It is conceivable that, according to these divergent functions, different types of microvilli exist, which display pronounced differences in their morphology and also in their molecular composition. The function(s) of the highly specialized microvilli of the male excurrent ducts, which selectively express the HE6/GPR64 receptor remain to be established.

\section{Materials and Methods}

\section{Human tissues}

Human epididymides were obtained with the authorization of the local ethical committee from two individual patients who underwent orchidectomy for the treatment of prostate 
carcinoma at local hospitals (courtesy of Drs M Davidoff and R Middendorff, University Hospital Hamburg-Eppendorf, Germany). The ethical principles for research involving human tissues as stated in the 52nd World Medical Association Declaration of Helsinki were strictly observed in each case. Proximal parts of the two pairs of epididymides were immersion fixed in Bouin's solution and embedded in paraffin for immunohistochemistry using standard procedures (see below).

\section{Mouse tissues}

Three pairs of testes plus epididymides were obtained from adult male mice (C57BL/6; Charles River, Sulzfeld, Germany) that had been killed by cardiac vascular perfusion (courtesy of Dr M Schweizer, ZMNH, University Hospital HamburgEppendorf, Germany). All animal housing and operation practices were in compliance with German Animal Welfare laws, and the Guiding Principles in the Care und Use of Laboratory Animals (DHEW Publication, NIH, 80-23) were observed in all cases. Briefly, after anaesthetization of the animals with Nembutal (65 mg/kg body weight) and initial perfusion with PBS solution $(0.9 \% \mathrm{NaCl}$ in $10 \mathrm{mM}$ phosphate buffer, $\mathrm{pH}$ 7.4) through the left cardiac ventricle, PLP solution (4\% paraformaldehyde, $75 \mathrm{mM}$ lysine- $\mathrm{HCl}, 10 \mathrm{mM}$ sodium periodate and $0.15 \mathrm{M}$ sucrose dissolved in $37.5 \mathrm{mM}$ sodium phosphate; McLean \& Nakane 1974) was perfused. After dissection, the perfusion-fixed organs were further fixed in PLP by immersion for $4 \mathrm{~h}$ at room temperature (RT) and subsequently overnight at $4{ }^{\circ} \mathrm{C}$. Fixed organs were then rinsed overnight at $4{ }^{\circ} \mathrm{C}$ in PBS containing 0.9 M sucrose. Testes plus epididymides were then embedded in Tissue-Tek OCT compound (Sakura Finetek Europe, Zoeterwoude, the Netherlands), mounted and frozen at $-25^{\circ} \mathrm{C}$.

\section{Primary antibodies and cell stainings}

Anti-peptide antibodies N2, A and mA23 had been raised in rabbits against discrete peptide epitopes of the HE6/GPR64 receptor protein, corresponding to an $\mathrm{N}$-terminal peptide sequence (N2), to a sequence from the second extracellular loop of the 7 TM region of human HE6/GPR64 (A) and the mouse HE6/GPR64 homologue (mA23) respectively. Their specificity was previously confirmed by peptide competition assays (Obermann et al. 2003, Davies et al. 2004). They were affinity purified and employed as previously described (Obermann et al. 2003). Mouse anti-ezrin (Zymed Laboratories, Inc., South San Francisco, CA, USA) and anti-acetylated tubulin clone 6-11B-1 (Sigma) monoclonal antibodies were employed for dual immunostaining procedures. Alexa-fluor 546-conjugated phalloidin (Molecular Probes Europe, Leiden, the Netherlands) was employed to specifically stain actin filaments (see below).

\section{Immunoperoxidase staining}

Paraffin sections $(4 \mu \mathrm{m})$ were obtained from proximal parts of human epididymides. A conventional peroxidase-anti-peroxidase (PAP)-avidin-biotin complex (ABC) combination method was adopted with the modifications as described (Balvers et al. 1998). Briefly, after passing through xylol and descending ethanols, sections were washed $2 \times 10 \mathrm{~min}$ in Trisbuffered saline (TBS; $0.05 \mathrm{M}$ Tris- $\mathrm{HCl}, 0.15 \mathrm{M} \mathrm{NaCl}, \mathrm{pH} 7.4$ ). Endogenous peroxidase was suppressed by incubation in $3 \%$ (v/v) $\mathrm{H}_{2} \mathrm{O}_{2}$ for $45 \mathrm{~min}$ at RT. Sections were then blocked with $10 \%(\mathrm{v} / \mathrm{v})$ normal goat serum for $1 \mathrm{~h}$ at RT. After rinsing in TBS, sections were incubated with anti-N2 and A antibodies at dilutions of 1:500-1:2000 in antibody dilution buffer (ADB; TBS containing $2 \%(\mathrm{v} / \mathrm{v})$ normal goat serum plus $0.05 \%(\mathrm{w} / \mathrm{v})$ BSA), overnight at $4{ }^{\circ} \mathrm{C}$; the corresponding pre-immune serum served as a control. After rinsing $3 \times 5 \mathrm{~min}$ in TBS, sections were incubated with biotinylated goat anti-rabbit IgG (Vector Laboratories, Burlingame, CA, USA), diluted 1:500 in ADB for $1 \mathrm{~h}$ at RT. After $3 \times 5 \mathrm{~min}$ rinsing in TBS, sections were then incubated in rabbit PAP complex (Dianova, Hamburg, Germany) $1: 500$ in ADB, for $1 \mathrm{~h}$ at RT. After $3 \times 5$ min of rinsing in TBS, these last two incubation steps were repeated, this time for only $30 \mathrm{~min}$ per step. After further brief rinsing in TBS, sections were incubated with $A B C$ complex (Vector Laboratories) for $1 \mathrm{~h}$ at RT. Specific signals were detected using DAB (Sigma) as chromogen and stopping the reaction by rapidly rinsing in tap water, followed by conventional haemalaun counterstaining. Sections were coverslipped in aqueous mounting medium and investigated by standard bright field microscopy (Nikon, Tokyo, Japan) and images captured with a digital camera (Leica DC 300; Leica Microsystems, Wetzlar, Germany).

\section{Immunofluorescence staining}

Cryosections $(8 \mu \mathrm{m})$ were obtained from mouse tissues (Reichert-Jung 2800 Frigocut, Leica Microsystems), collected on Superfrost Plus charged microscope slides (Menzel $\mathrm{GmbH}$, Braunschweig, Germany), air-dried and stored at $-20{ }^{\circ} \mathrm{C}$ until use. Sections were rehydrated in PBS solution (see above) for $15 \mathrm{~min}$ and then treated with 1\% SDS (wt/vol) for antigen retrieval as described (Brown et al. 1996). Sections were washed $3 \times 10 \mathrm{~min}$ in PBS and blocked with $10 \%(\mathrm{v} / \mathrm{v})$ normal goat serum for $1 \mathrm{~h}$ at RT, followed by a 2-h incubation with the primary antibodies at RT employing the appropriate dilutions as specified. Anti-acetylated tubulin was employed at 1:200 in ADB and anti-ezrin at 1:100 in ADB. Slides were rinsed $3 \times 5$ min in PBS, then the corresponding secondary antibodies were applied for $1 \mathrm{~h}$ at RT, and the slides rinsed again $3 \times 5 \mathrm{~min}$ in fresh PBS. The following secondary antibodies and amplification systems were employed: Cy2-or Cy3-conjugated goat anti-rabbit or anti-mouse IgGs (Jackson ImmunoResearch Laboratories, West Grove, PA, USA) respectively were employed at a final concentration of $1.5 \mu \mathrm{g} / \mathrm{ml}$. For dual labelling with antibodies raised in different species, the primary antibodies were applied sequentially at the appropriate concentration, followed by the corresponding secondary antibodies. At dilutions higher than 1:100 of the mA23 antibody, tyramide signal amplification was employed for this antibody using a TSA kit (Molecular Probes) that contained Alexa-fluor 488 tyramide and horse radish peroxidaseconjugated anti-rabbit IgG. Slides were rinsed in PBS for 10 min, immersed in $0.25 \% \mathrm{H}_{2} \mathrm{O}_{2}$ in $\mathrm{PBS}$ for $60 \mathrm{~min}$, rinsed in 
PBS for 5 min, and incubated with SDS and blocking solutions as described above. TSA (Molecular Probes) was then performed according to the supplier's instructions. Alexafluor 546-conjugated phalloidin (Molecular Probes) was employed according to the suggestions of the supplier at a final concentration of 200 units $/ \mathrm{ml}$, which is equivalent to $\sim 6.6 \mu \mathrm{M}$. Slides were rinsed $3 \times 10 \mathrm{~min}$ in fresh PBS and then coverslipped in fluorescent mounting medium (DAKO, Hamburg, Germany).

\section{Laser confocal microscopy}

Slides were examined for standard fluorescence and LaserScan Confocal imaging on a Leica TCS SL confocal microscopy system using Leica Confocal Software version 2.00. The Leica DM IRE2 fluorescence microscope was equipped with PlanApochromat $10 \times, 40 \times$ and $63 \times$ objectives; the $63 \times / 1.2 \mathrm{~W}$ immersion oil objective was used to acquire the final confocal images. Differential interference contrast was used for transmitted images. Visualization of green fluorophore (Cy2, Alexa-fluor 488) excitation at $488 \mathrm{~nm}$ was achieved by using an argon laser (Leica). Red fluorophore (Cy3, Alexa-fluor 546) excitation at $543 \mathrm{~nm}$ was achieved by using a helium/neon laser (Leica). Energy emission in the form of light by green fluorophores (510$520 \mathrm{~nm}$ ), and red fluorophores (570-590 nm) was detected using independent photomultiplier tubes (PMTs). To calculate optimum PMT settings for each laser line, the glow-over-under option of the Leica Confocal Software was used to adjust brightness and minimize autofluorescence. The pinhole was set at 1 Airy unit for captured confocal images. Colour channels for the final doublelabel images were captured sequentially and then merged using the Leica TCS NT software. For controls, identical PTM and pinhole settings were used.

\section{Declaration of interest}

The authors declare that there is no conflict of interest that would prejudice the impartiality of this scientific work.

\section{Funding}

The work was supported by the German Research Association (DFG, grant contract KI-317/9) and by the Ernst Schering Research Foundation and Rockefeller Foundation as part of the AMPPA network.

\section{Acknowledgements}

We gratefully acknowledge the skilled technical assistance of Ms Marga Balvers, IHF Institute for Hormone and Fertility Research, Hamburg, Germany. We are indebted to Prof. Dr med. F Leidenberger, founder of the former IHF, who provided excellent working facilities. We are also grateful to Prof. Dr med. A -F Holstein, and to Prof. Dr med. W Schulze, University Hospital Hamburg-Eppendorf, Hamburg, Germany, for helpful discussions.

\section{References}

Aumüller G, Wilhelm B \& Seitz J 1999 Apocrine secretion - fact or artifact? Annals of Anatomy 181 437-446.

Balvers M, Spiess AN, Domagalski R, Hunt N, Kilic E, Mukhopadhyay AK, Hanks E, Charlton HM \& Ivell R 1998 Relaxin-like factor expression as a marker of differentiation in the mouse testis and ovary. Endocrinology 139 2960-2970.

Berryman M, Franck Z \& Bretscher A 1993 Ezrin is concentrated in the apical microvilli of a wide variety of epithelial cells whereas moesin is found primarily in endothelial cells. Journal of Cell Science 105 1025-1043.

Brown D, Lydon J, McLaughlin M, Stuart-Tilley A, Tyszkowski R \& Alper S 1996 Antigen retrieval in cryostat tissue sections and cultured cells by treatment with sodium dodecyl sulfate (SDS). Histochemistry and Cell Biology 105 261-267.

Chen J \& Wagner MC 2001 Altered membrane-cytoskeleton linkage and membrane blebbing in energy-depleted renal proximal tubular cells. American Journal of Physiology. Renal Physiology 280 F619-F627.

Clulow J, Hansen LA \& Jones RC 1996 In vivo microperfusion of the ductuli efferentes testis of the rat: flow dependence of fluid reabsorption. Experimental Physiology 81 633-644.

Davies B, Baumann C, Kirchhoff C, Ivell R, Nubbemeyer R, Habenicht UF, Theuring F \& Gottwald U 2004 Targeted deletion of the epididymal receptor HE6 results in fluid dysregulation and male infertility. Molecular and Cellular Biology 24 8642-8648.

Davies B, Behnen M, Cappallo-Obermann H, Spiess AN, Theuring F \& Kirchhoff C 2007 Novel epididymis-specific mRNAs down-regulated by HE6/Gpr64 receptor gene disruption. Molecular Reproduction and Development 74 539-553.

Du Z, Duan Y, Yan Q, Weinstein AM, Weinbaum S \& Wang T 2004 Mechanosensory function of microvilli of the kidney proximal tubule. PNAS 101 13068-13073.

Gottwald U, Davies B, Fritsch M \& Habenicht UF 2006 New approaches for male fertility control: HE6 as an example of a putative target. Molecular and Cellular Endocrinology 250 49-57.

Hermo L \& Jacks D 2002 Nature's ingenuity: bypassing the classical secretory route via apocrine secretion. Molecular Reproduction and Development 63 394-410.

Hermo L, Oko R \& Morales CR 1994 Secretion and endocytosis in the male reproductive tract: a role in sperm maturation. International Review of Cytology 154 106-189.

Hess RA 2003 Estrogen in the adult male reproductive tract: a review. Reproductive Biology and Endocrinology 1 52-65.

Hess RA \& Nakai M 2000 Histopathology of the male reproductive system induced by the fungicide benomyl. Histology and Histopathology 15 207-224.

Hess RA, Bunick D, Lee KH, Bahr J, Taylor JA, Korach KS \& Lubahn DB 1997 A role for oestrogens in the male reproductive system. Nature 390 509-512.

Höfer D \& Drenckhahn D 1996 Cytoskeletal differences between stereocilia of the human sperm passageway and microvilli/stereocilia in other locations. Anatomical Record 245 57-64.

Holmes JL, Van Itallie CM, Rasmussen JE \& Anderson JM 2006 Claudin profiling in the mouse during postnatal intestinal development and along the gastrointestinal tract reveals complex expression patterns. Gene Expression Patterns 6 581-588.

Holstein AF 1969 Morphologische Studien am Nebenhoden des Menschen. In Zwanglose Abhandlungen aus dem Gebiet der normalen und pathologischen Anatomie, vol 20, pp 1-91. Eds W Bargmann \& W Doerr. Stuttgart: Thieme Verlag.

Huang T, You Y, Spoor MS, Richer EJ, Kudva VV, Paige RC, Seiler MP, Liebler JM, Zabner J, Plopper CG et al. 2003 Foxj1 is required for apical localization of ezrin in airway epithelial cells. Journal of Cell Science 116 4935-4945.

Ilio KY \& Hess RA 1992 Localization and activity of $\mathrm{Na}+, \mathrm{K}(+)$-ATPase in the ductuli efferentes of the rat. Anatomical Record 234 190-200.

Ilio KY \& Hess RA 1994 Structure and function of the ductuli efferentes: a review. Microscopy Research and Technique 29 432-467.

Inai T, Sengoku A, Guan X, Hirose E, lida H \& Shibata Y 2005 Heterogeneity in expression and subcellular localization of tight junction proteins, claudin-10 and -15, examined by RT-PCR and immunofluorescence microscopy. Archives of Histology and Cytology 68 349-360. 
Kirchhoff C, Obermann H, Behnen M \& Davies D 2006 The role of the epididymal receptor HE6 in the regulation of sperm microenvironment. Molecular and Cellular Endocrinology 250 43-48.

Kujala M, Hihnala S, Tienari J, Kaunisto K, Hästbacka J, Holmberg C, Kere J \& Höglund P 2007 Expression of ion transport-associated proteins in human efferent and epididymal ducts. Reproduction 133 775-784.

Lubahn DB, Moyer JS, Golding TS, Couse JF, Korach KS \& Smithies O 1993 Alteration of reproductive function but not prenatal sexual development after insertional disruption of the mouse estrogen receptor gene. PNAS 90 11162-11166.

Man SY, Clulow J \& Jones RC 2003 Signal transduction in the ductuli efferentes testis of the rat: inhibition of fluid reabsorption by cyclic adenosine 3', 5'-monophosphate. Biology of Reproduction 69 1714-1718.

Mazzochi C, Benos DJ \& Smith PR 2006 Interaction of epithelial ion channels with the actin-based cytoskeleton. American Journal of Physiology. Renal Physiology 291 F1113-F1122.

McLean IW \& Nakane PK 1974 Periodate-lysine-paraformaldehyde fixative. A new fixation for immunoelectron microscopy. Journal of Histochemistry and Cytochemistry 22 1077-1083.

Obermann H, Samalecos A, Osterhoff C, Schröder B, Heller R \& Kirchhoff C 2003 HE6, a two-subunit heptahelical receptor associated with apical membranes of efferent and epididymal duct epithelia. Molecular Reproduction and Development 64 13-26.

Osterhoff C, Ivell R \& Kirchhoff C 1997 Cloning of a human epididymisspecific mRNA, HE6, encoding a novel member of the seven transmembrane-domain receptor superfamily. DNA and Cell Biology 16 379-389.

Pastor-Soler N, Pietrement C \& Breton S 2005 Role of acid/base transporters in the male reproductive tract and potential consequences of their malfunction. Physiology 20 417-428.
Piperno G \& Fuller MT 1985 Monoclonal antibodies specific for an acetylated form of alpha-tubulin recognize the antigen in cilia and flagella from a variety of organisms. Journal of Cell Biology 101 2085-2094.

Robaire B \& Hermo L 1988 Efferent ducts, epididymis, and vas deferens: structure, functions, and their regulation. In The Physiology of Reproduction, 5 edn, pp 999-1080. Eds E Knobil \& JD Neill. New York: Raven Press.

Schwabe T, Bainton RJ, Fetter RD, Heberlein U \& Gaul U 2005 GPCR signaling is required for blood-brain barrier formation in Drosophila. Cell 123 133-144.

Setchell BP, Scott TW, Voglmayr JK \& Waites GM 1969 Characteristics of testicular spermatozoa and the fluid which transports them into the epididymis. Biology of Reproduction 1 (Supplement 1) 40-66.

Da Silva N, Pietrement C, Brown D \& Breton S 2006 Segmental and cellular expression of aquaporins in the male excurrent duct. Biochimica et Biophysica Acta 1758 1025-1033.

Vollrath MA, Kwan KY \& Corey DP 2007 The micromachinery of mechanotransduction in hair cells. Annual Review of Neuroscience $\mathbf{3 0}$ 339-365.

Wieland T 198750 Years of phalloidine: its discovery, characterization and current and future applications in cell research. Die Naturwissenschaften 74 367-373.

Yeung CH, Cooper TG, Bergmann M \& Schulze H 1991 Organization of tubules in the human caput epididymidis and the ultrastructure of their epithelia. American Journal of Anatomy 191 261-279.

Received 19 February 2008

First decision 14 March 2008

Revised manuscript received 15 April 2008

Accepted 8 May 2008 